\title{
EL CUERPO COMO POSIBILIDAD DE LA VIDA: EL MODO DE DESPLIEGUE DEL MUNDO CONCRETO
}

Body as a possibility of life: The mode of deployment of a concrete world

Felipe Johnson*

Resumen

El intento de desarrollar una ontología de la corporalidad humana realzando el fenómeno cuerpo humano en su propio carácter de ser, debe confrontarse con un problema fundamental: determinar el modo auténtico cómo el cuerpo humano se despliega, asegurando así un acceso a su sentido más propio. Tomando como punto de partida la analítica del Dasein y las consideraciones metódicas que Martin Heidegger ha desarrollado a lo largo de su obra. El presente artículo se propone esbozar algunas líneas directrices que puedan contribuir a emprender dicha tarea, haciendo énfasis en aquellos problemas metódicos fundamentales que surgen en el intento de desarrollar una ontología de la corporalidad.

Palabras clave: Cuerpo humano, ontología de la corporalidad, Dasein, Heidegger, fenomenología. Abstract

The attempt to develop an ontology of the human corporality emphasizing her own character of being, must be confronted with a fundamental problem: to determine the authentic way of how the human body can unfold itself assuring an access to its more proper sense. The present article, takes as a point of departure the analytics of Dasein and the methodical considerations of Martin Heidegger, and aims to point out some guidelines of research, which may contribute to face up the problem, especially emphasizing in those methodical aspects that arise when an ontology of the corporality is developed.

Key words: Human body, ontology of corporality, Dasein, Heidegger, phenomenology.

CUERPO Y COSTUMBRE: ESBOZO DE UNA MANERA FILOSÓFICA DE PRESENTAR EL CUERPO HUMANO

A la pregunta filosófica por la corporalidad humana subyace un peligro inminente; a saber, en el intento de responder a ella, esta misma pregunta puede auto-anularse. En efecto, en el momento de preguntar sobre la esencia del cuerpo humano existe la posibilidad de asumir, sin más, una comprensión del mismo sin que nos detengamos a pensar si dicha comprensión no ha distraído ya nuestra mirada de aquello que efectivamente debíamos interrogar. En este sentido, la formulación de la pregunta filosófica por el cuerpo humano tiene la posibilidad de permanecer en un modo acostumbrado de entender la corporalidad, en general, y no pretender otra cosa sino continuar explicitando lo que esta comprensión previa ha predeterminado como sus posibles características. Así, podemos plantear que el primer problema con el que una ontología de la corporalidad debe confrontarse; se 


\section{Felipe Johnson}

refiere a una cierta ceguera en relación al carácter pre-comprensivo de la costumbre. Sobre esto, sin embargo, volveremos a continuación. Mientras, queremos subrayar que las presentes consideraciones se han propuesto exponer el fenómeno cuerpo humano intentando realizar una irrupción en dicha costumbre, de manera que éste pueda ser expuesto en su manera de despliegue propiamente existencial. Ahora bien, debemos decir que nuestras discusiones se moverán al interior de las consideraciones realizadas por Heidegger en torno al Dasein, y a las precisiones metódicas que ha hecho en torno al filosofar. No obstante, no pretenderemos exponer en un sentido doctrinario lo que Heidegger mismo sostuvo acerca de esta dimensión humana, sino, más bien, intentaremos, con la ayuda de su pensar, comprender el fenómeno mismo de la corporalidad. Comenzaremos, entonces, con algunas precisiones sobre la costumbre.

La primacía de la costumbre en relación al conocimiento de las cosas, en general, es destacada ya por Aristóteles en Metafisica: "y es que lo habitual, en efecto, es más fácilmente cognoscible. Y cuánta fuerza tiene lo habitual, lo ponen de manifiesto, a su vez, las leyes; en éstas lo legendario e infantil tiene más fuerza, a causa de la costumbre, que el conocimiento acerca de ellas" (1957:995a). Queremos detenernos en dos caracteres de esta cita que son subrayados en relación a las aludidas leyes: el primero es su carácter de legendario o fantástico (mythóde) y; el segundo, lo infantil o pueril (paidarióde) en ellas. La fuerza de la costumbre pareciera implicar, en este contexto, una aceptación que no cuestionaría más aquello que aprendemos. La costumbre se consolidaría al modo de una mera transmisión, de una herencia que debe ser respetada. Es aquello que sería asumido de la manera como un niño asume, sin más, aquel mundo donde vive, justamente, porque quiere continuar su trato con aquello que es de su preocupación al interior de ese mundo. La costumbre se constituiría, en definitiva, en un deber ser, en una norma, que ha de ser considerada inmediatamente como el único modo posible de hablar de las cosas. Ambos términos indican, en consecuencia, que el ethos, es decir, la forma cómo estamos acostumbrados a escuchar acerca de las cosas, se caracteriza por traer consigo la posibilidad de dejar de lado el objeto por conocer.

El problema al que nos enfrentamos en esta fase introductoria es buscar un punto de partida para una ontología del cuerpo humano. No obstante, si no atendiésemos a las advertencias hechas arriba podríamos afirmar, sin más, que el modo acostumbrado de hablar sobre la corporalidad sería un comienzo pertinente para esclarecer en qué se caracteriza su ser más propio. Pero ya hemos visto que la costumbre de hablar del cuerpo no es confiable, pues podría ocultarnos precisamente qué es el cuerpo en cuanto tal. No obstante, es también cierto que el hecho de comenzar por la costumbre podría ofrecernos una ventaja, a saber, atendiéndole podríamos acceder al fenómeno en cuestión, en principio mostrando si nos lo presenta adecuadamente. En este sentido, la 
costumbre podría ser el inicio de nuestras reflexiones; sin embargo, sólo si no la asumiéramos para quedarnos, como lo hace el niño, en el mundo que ella nos abre, sino, por el contrario, si es que somos capaces de tomar distancia de ella y exponer, desde dicha distancia, cómo es que ahí se nos presenta el cuerpo humano. No confundiremos, entonces, el cuerpo de la costumbre con la constitución del cuerpo en cuanto tal. Tomaremos el cuerpo acostumbrado sólo para explicitar los problemas que de él se derivan, y desde ahí podremos decidir si es que el cuerpo auténtico no es algo radicalmente distinto a lo que la costumbre nos muestra. Este movimiento desde el cuerpo acostumbrado al cuerpo mismo es aquello a lo que llamábamos al comienzo irrupción. ${ }^{1}$

Para comenzar, tomemos en consideración el siguiente ejemplo: cuando tengo sed, tomo aquel vaso de agua que he puesto sobre mi escritorio, de manera que extiendo mi mano junto con mi brazo para acceder a él y acercarlo a mis labios. En primera instancia, pareciera ser un hecho innegable que tanto mi mano como mi brazo son aquellos agentes necesarios para poder beber el agua. La composición física, anatómica de mi cuerpo, pareciera ganar primacía, y esto no sólo en esta acción específica, sino que en toda acción que yo quisiera ejecutar. Por otra parte, podemos decir que el traslado de mi mano al objeto por alcanzar tiene lugar en un espacio determinado. No sólo mi constitución física, sino que también, mi presencia en un espacio geométrico específico se presentan como instancias que pertenecen al beber agua.

Estas primeras tres nociones (a saber, la de sujeto, objeto y de espacio) son, pues, aquellas categorías que podrían ser útiles para exponer formalmente el ejemplo que planteábamos. De hecho, este es el modo cómo la costumbre nos enseña el fenómeno del movimiento de un cuerpo hacia otro, esto es: como un traslado o cambio de lugar desde un punto A hacia un punto B en un espacio homogéneo. Nos encontramos acá con un modo del movimiento que Aristóteles denominó phorá, y cuyos caracteres fundamentales son el arriba, el abajo, como también lo liviano y lo pesado. ${ }^{2}$

A la consideración del movimiento corporal como traslado subyace, sin embargo, un problema fundamental para una ontología de la corporalidad: en esta consideración se ha pasado por alto su problema por excelencia. No se ha

\footnotetext{
${ }^{1}$ Como el mismo Aristóteles sostiene en el libro V de Metafisica (1013a 4), a veces lo primero es tal en relación al aprendizaje; sin embargo, no en cuanto a lo que la cosa misma es en su constitución. Sostenemos que aquello que el cuerpo mismo es en su ser es, en relación al conocimiento, algo que se conocerá posteriormente, porque es aquello que la costumbre misma oculta. Si elegimos, entonces, la costumbre como punto de partida, será para detectar cuáles son los problemas que ella presenta en relación a la corporalidad, de manera que una tematización filosófica de la misma pueda desarrollarse.

${ }^{2}$ Cfr., Física (1956:201a 7-8). Véase, además, los Zollikoner Seminare (Heideger, 1994b:201), donde se expone el concepto metabolé como la determinación formal del movimiento en general y que, según los distintos modos de ser (categorías), se dividirían en génesis-phthorá; aúxesis - phthisis; alloiosis; phorá.
} 


\section{Felipe Johnson}

planteado la pregunta explícita por el ser del ente en cuestión. En efecto, cuando en su Física, Aristóteles expone los tipos de movimiento debe enfatizar que hay un modo de ser específico, una categoría, en virtud de la cual acaece un tipo de cambio determinado. Es aquí donde se indica que el traslado (phorá) corresponde al modo de ser de la cantidad (posón) (1956:201a7-8). La advertencia de Aristóteles nos hace entender que en el momento en que hemos expuesto el movimiento corporal como traslado, hemos instalado nuestra mirada en un modo de ser del cuerpo, sin que nos hayamos preguntado de antemano si ese modo de ser, la cantidad, es efectivamente el apropiado para entender la corporalidad humana. En otras palabras, al acto de explicar cuáles son aquellos atributos característicos de la corporalidad le precede necesariamente una tematización primaria que dé cuenta de aquel horizonte desde dónde dichas consideraciones deberán desarrollarse. Estas reflexiones previas son, pues, aquello que se articula como la pregunta por el modo de ser propio de la corporalidad. Antes de entender el movimiento corporal como traslado es necesario, en definitiva, preguntar si según la naturaleza más propia del cuerpo es posible hablar luego de traslado.

Debemos destacar, por lo demás, que en la noción de movimiento como traslado tanto el sujeto como el objeto se caracterizan por ser independientes entre sí, ya que el cuerpo deberá recorrer toda aquella distancia que hay entre él y el objeto para acceder a éste. En este sentido, pareciera ser necesario buscar algún tipo de enlace entre ambos, que vaya — por decirlo así- más allá del espacio homogéneo que los une. Por esta vía sería factible realzar la unión que existe entre mí, es decir, el cuerpo anatómico, y el vaso de agua en el sentido de tener sed. En otras palabras: en un contexto dado mi cuerpo anatómico pareciera adquirir una disposición requerida para trasladarse de manera efectiva en aquel contexto, de manera que dos objetos (mi cuerpo y el vaso) puedan relacionarse entre sí. El realce de dicha relación entre ambos pareciera ser un avance en la explicación del ejemplo expuesto. Es posible, según lo observado, destacar una relación vital: el contexto en el que el movimiento de la mano se ejecuta. Según nuestro ejemplo, la sed vendría a ser acá aquel enlace, podríamos llamarlo, existencial, una legalidad vital, entre un Yo, entendido como algo contenido en un cuerpo, y el objeto de nuestra atención. Una legalidad vital según la cual mi cuerpo adquiere esta disposición determinada y no otra. ${ }^{3}$

De esta manera, pareciera ser que hemos aprehendido el fenómeno de una manera radical. El espacio geométrico donde se desenvuelve el traslado de la

\footnotetext{
${ }^{3}$ Esto ha significado ser, por lo demás, el aporte de aquellas fenomenologías de la corporalidad como la de Merleau-Ponty (1945) o Waldenfels (2000) para quienes la legalidad vital arriba mencionada sería en su propiedad el modo cómo el cuerpo está vivo. En su propia función éste se desplegaría como el poder de un mundo determinado, es decir, como aquella realización de los hilos intencionales del mundo. Así, por ejemplo, Merleau-Ponty describe cómo es que el pianista, en el momento de interpretar una pieza musical, se vuelve una unidad con el instrumento musical, donde dicha unidad es denominada "habitud" (l' habitude) (1945:170).
} 
mano adquiriría sus propios límites, puesto que éste, según el contexto de la sed - un contexto vivido - sólo se proyectaría entre mis labios y la mesa. Podríamos decir, incluso, que hay una primera motivación que posibilitaría la emergencia de un campo de acción determinado. De este modo, el cuerpo se caracterizaría por ser la ejecución de aquellas acciones que vienen ya reglamentadas por una motivación subjetiva, y su disposición, la disposición corporal, no sería más que una configuración determinada según su contexto vital.

Advertimos que una manera apropiada de acceder a nuestro fenómeno y aprehenderlo en su propia vitalidad - y esto, para caracterizar el modo de ser de dicha vitalidad - es comprendiéndolo en aquel contexto existencial que él asume como un habituarse (Merleau-Ponty, 1945:168). Desde esta perspectiva pareciera que hemos superado un estadio que las consideraciones corporales por parte de la filosofía han querido en la actualidad descartar, como lo es la comprensión cartesiana del cuerpo humano en tanto máquina inerte, que conduce, por cierto, a la interpretación mecanicista de todo tipo de fenómenos corporales (Waldenfels, 2000:113) Se hace, así, patente la relevancia que existe en el hecho de considerar al cuerpo en relación con su entorno: el realce de dicha relación en sí, pareciera ser, en efecto, el campo fenoménico apropiado para toda consideración filosófica de la corporalidad.

Indaguemos aún más en este primer avance efectuado y veamos hasta qué punto debemos sentirnos seguros con las apreciaciones hechas. La primera pregunta que podríamos plantearnos sería la siguiente ¿Cuando muevo mi mano para alcanzar el vaso de agua, qué es lo que se mueve? ¿Se mueve algo que soy o que no soy yo? En caso que respondiéramos que esa mano no soy yo trae consigo algunas dificultades, pues si ella y mi brazo no son yo ¿Hasta qué punto de mi cuerpo anatómico deberé considerar que sí lo soy? Ahora bien, en el caso que resolvamos el problema diciendo: mi mano efectivamente soy yo, no deja tampoco de ser arriesgado. Pues, incluso, si dijéramos que yo soy todo mi cuerpo, nos aparece el problema de decidir ahora si es que hay tantas partes del yo como miembros y segmentos de mi cuerpo. Vemos, entonces, que la comprensión del cuerpo humano como una entidad física, extensa, trae consigo un problema difícilmente solucionable, a saber, el esclarecimiento de los límites del yo con respecto al cuerpo anatómico y, más aún, la pertenencia del cuerpo a un yo.

Por otra parte, es la espacialidad denominada como vital, es decir, el campo de acción de un cuerpo vivo lo que también presenta dificultades. ¿Cómo es, pues, que este campo de acción, el así llamado medio, puede dar cuenta de lo que es mi cuerpo? Deberemos decir que la determinación del cuerpo en cuanto aquello que se articula en una situación, los caracteres propios que rinden cuenta de esta posibilidad, no vienen dados desde la noción de contexto vital, sino que, más bien, la suponen. Sólo en la medida en que el cuerpo sea entendido principalmente como algo adaptable a un contexto y, por ende, igualmente autónomo con respecto a él, es 


\section{Felipe Johnson}

posible, después, ponerlo en relación con el concepto de contexto. Sin embargo, la explicitación del contexto en cuanto contexto no arroja luces sobre el ser del cuerpo, pues se trata de un fenómeno distinto. El realce de una ley vital no es más que el intento de unir dos instancias primariamente independientes (sujeto extenso y objeto) recurriendo a una tercera instancia igualmente exterior al ser del cuerpo, a saber, aquella legalidad que entendíamos anteriormente como vital.

Como podemos ver, la determinación del ser del cuerpo como objeto extenso traspasa a las explicaciones de fenómenos corporales puntuales todas las dificultades que implica el intento de unir dos entes que en su ser ya existen separados. Si comprendemos que al sujeto volente le pertenece una dimensión física (su cuerpo anatómico), no podemos liberar sus consideraciones de los caracteres propios de aquello que está delimitado por una figura espacial, que sería el límite de su ser. Una ontología de la corporalidad muestra, en este punto, la urgencia de ser rearticulada, pues ella es la pregunta explícita por aquel fundamento para todas aquellas consideraciones sobre los atributos de la corporalidad humana. No estaría demás decir, entonces, que la aludida costumbre de entender el cuerpo humano no es sólo un conjunto de opiniones que se tiene sobre el mismo: ella implica, fundamentalmente, la determinación del ser del ente en cuestión, la delimitación de aquella dirección temática principal según la cual, luego, podemos hablar de sus características particulares. La costumbre tiene, en este sentido, carácter thético, por lo cual es su modo de fijar entes en su ser lo que debe volverse cuestionable.

INDICACIONES PARA LA DETECCIÓN DEL CAMPO FENOMÉNICO PROPIO DE LA CORPORALIDAD

Creemos que una advertencia de Heidegger puede ayudarnos a continuar nuestras consideraciones: "Y sólo porque los "sentidos" pertenecen ontológicamente a un ente, el cual tiene el modo de ser del estar-en-el-mundo sintiéndose en él de alguna manera, pueden ser "tocados" y "tener sentido para", de tal manera que lo que toca se muestra en la afección” (2001:137) (Trad., mía).

Lo que queremos destacar de este fragmento es el hecho de que los sentidos, es decir, la percepción sensible, "pertenezca" ontológicamente a un ente. La pertenencia aquí aludida indica que la dirección del despliegue mismo, del modo cómo algo es percibido, posee en sí una manera de realización específica. Habría, entonces, una relación necesaria en cómo es que el ente percibe y el ser del mismo ente, de manera que aquella forma particular cómo la percepción sensible se despliega no podría ser expuesta adecuadamente si entendemos dicha pertenencia como si una función dependiera del agente que la

\footnotetext{
4 "Und nur weil die "Sinne" ontologisch einem Seienden zugehören, das die Seinsart des befindlichen Inder-Welt-seins hat, können sie "gerührt" werden und "Sinn haben für", so daß das Rührende sich in der Affektion zeigt”. Cfr., además, Martin Heidegger (2001:147), donde se indica una relación entre los "sentidos" (percepción sensible) y un campo de cosas por descubrir "sensiblemente" (Entdeckungsbezirk).
} 
ejecuta, pues esta interpretación habría asumido una separación entre ambos, imponiendo un nexo externo, esto es: una relación causa-efecto. La mentada pertenencia que queremos destacar del fragmento de Sein und Zeit es radical. No señala una relación entre un agente físico y la acción por éste ejecutada, sino más bien, cómo es que el percibir se funda en un modo de ser específico, es decir, cómo es que el despliegue de la percepción posee los caracteres de un modo de ser determinado: este es justamente su carácter ontológico.

Con respecto al problema del cuerpo diremos, entonces: cuerpo habrá sólo al interior de esta pertenencia con el ser de aquello de lo cual es cuerpo. Si el problema es ahora la corporalidad humana, se trata, entonces, de investigar en qué sentido una manera de ser específica, lo humano, posee un tipo de cuerpo particular. Una ontología de la corporalidad advierte la necesidad de presentar una dimensión de un ente en su más rigurosa especificidad. La pregunta, en este sentido, es ¿Qué es lo que caracteriza al cuerpo del ser humano a diferencia de los cuerpos de otros seres vivos y, por cierto, de los cuerpos inertes? Pues, será según aquel modo de ser específico cómo es que este cuerpo, más que ser considerado como la materia de un ente físico, por cierto, indistinto de otros, podrá ser entendido como una manera propia de concretud. Entenderemos, en efecto, que cuerpo es precisamente la materia de un ente, pero el concepto materia no deberemos identificarlo, ahora, con la dimensión sólida de una cosa, pues ente no es un concepto que sólo se vincula con meras cosas físicas, sino, más bien, con aquello que desplegándose en un determinado modo de ser, posee límites de una naturaleza particular (Heidegger 1994a:195). Así, una ontología de la corporalidad humana deberá comprender que aquello a lo cual denomina con el término cuerpo es aquella concreción propia de lo humano. En definitiva: cuerpo es la materia de un ente, entendido como aquello que según el modo de ser específico de aquel ente se presenta en límites determinados.

Con esto hemos ganado algunos resultados metódicos importantes: la consideración filosófica de la corporalidad no es un saber de dicho ente que ha asumido de antemano que el ente es así y no de otra manera, pues precisamente ese acostumbrado ser así y no de otra manera es lo primero que debe volverse cuestionable. Esto lleva a entender, por otra parte, que cuerpo humano implica el estudio de un fenómeno al interior de un modo de ser específico, en tanto ontología es el realce de lo diferencial de cada ente. Por último, entendemos que cuerpo - de alguna manera - pertenece al hombre, por lo que a continuación deberemos presentar nuestro fenómeno principalmente desde el modo de ser de lo humano.

Volvamos nuevamente a nuestro ejemplo, y veamos de qué manera podemos presentar el fenómeno cuerpo humano atendiendo a los problemas arriba destacados. Considerando el modo inmediato cómo bebemos agua, advertimos que muchas veces el vaso, mi mano, y en realidad mi cuerpo anatómico completo pareciera en principio no tener relevancia. Cuando bebemos agua estamos, por así 


\section{Felipe Johnson}

decirlo, entregados al "saciar la sed". Entregado, viviendo mi beber agua como tal, pareciera que mis manos, mi brazo y el vaso de agua de alguna manera desaparecen. Este beber agua que ahora queremos explicitar corresponde a aquel actuar que está completamente arrojado a realizarse. Inmerso en el beber agua no pongo atención en mi cuerpo anatómico, ni siquiera en el agua, sino más bien en la realización del beber.

Nos hallamos, ahora, frente a dos niveles según los cuales podríamos considerar nuestro ejemplo. Un nivel inmediato, en donde todo agente físico parece ser descartado. Y otro, en el cual brazo, mano y agua se hacen manifiestos. Si, ahora bien, mientras bebo agua, pongo atención "a lo que hago", con el interés, por ejemplo, de describirlo, es entonces cuando la mano y el vaso de agua vuelven a aparecer. Sin embargo, cuando hago esto, ya no estoy en el nivel inmediato que ahora está en discusión: soy — por decirlo asíexpulsado de él. ¿Diremos ahora que el fenómeno del cuerpo sólo pertenece a este nivel tardío en donde lo anatómico se muestra? Una posible respuesta pareciera ser la siguiente: mientras estoy entregado completamente al beber agua, estoy tan ocupado con ello, que no pongo atención en mi cuerpo. Éste estaría, en efecto, también en este nivel inmediato que mencionamos, pero de manera implícita y a la espera de que yo me fije nuevamente en él. Sin embargo, con esta respuesta sobreviene una dificultad: aún insistimos en que mi $Y o$ es algo encapsulado en un cuerpo físico y, en cuanto encapsulado, lo entendemos mediante la manera de ser de una mera cosa presente en un espacio geométrico, volviéndose imposible proponer una relación con el objeto que evite recurrir a una ley externa que enlace a ambos.

Nuestra discusión ha mostrado que el beber agua en aquel nivel inmediato no exhibe con claridad cierto tipo de instancias como el vaso o el cuerpo anatómico ¿Debemos decir que su inmediatez se caracteriza sólo por una incapacidad de exponer con exactitud estos elementos? Inmediatamente podríamos descartar esta posibilidad, si comprendemos que dicha inmediatez es un momento anterior a la detección de instancias como sujeto, objeto y espacio. Primero ha debido ocurrir este tipo de trato inmediato con el mundo para que, luego, hablemos de sus elementos constitutivos. En este punto es donde vemos una distinción clara entre aquello que Heidegger denomina esfera preteórica y teórica y que se refieren, estrictamente, a modos de relación con el mundo (1992:94ss).

A partir de las consideraciones anteriores deberemos entender que esta inmediatez es, justamente, aquello que delata la vida que hay en nuestro ejemplo; la vida que hay en toda acción fáctica que realizamos en la cotidianeidad. Dicha inmediatez en el trato con el mundo es lo que se nos muestra como el campo fenoménico primario al interior del cual el cuerpo humano se muestra en su más propia vitalidad. En la inmediatez, como veíamos anteriormente, no aparece el cuerpo anatómico, lo que, no obstante, no significa que algo así como cuerpo no esté 
presente: es sólo que el cuerpo en este nivel inmediato se nos presenta como algo radicalmente distinto a un ente físico, por lo que su modo de ser sería algo radicalmente distinto a lo que Heidegger llamó Vorhandenheit (mera presencia espacial). ${ }^{5}$ La vida pareciera ser, en este sentido, algo en lo que estamos arrojados, inmersos, y que cuando tomamos distancia para exponerla, cuando nos abstraemos de ella, desvivificamos también lo que hemos vivido. Precisamente, a este proceso de desvivificación o Entlebungsproze $\beta$ —denominado, así, por Heidegger (1999:96) nos referíamos cuando decíamos que, en el momento de atender a lo que hacemos en el acto de beber, "somos expulsados" de la inmediatez de nuestra vivencia.

El campo fenoménico propio para una ontología de la corporalidad comienza, así, a revelar cuál es ese nivel de relación de la vida con los entes que debe ser tematizado. Nuestras consideraciones nos ayudan a entender, además, que en el nivel de una relación inmediata con el mundo lo que gana primacía fenoménica es la acción misma, lo que ahora, atendiendo a nuestro ejemplo, podríamos exponer en sentido verbal, a saber, como el beber. Dicho término no sólo indica el momento exacto cuando llevo el agua a mis labios, sino que aprehende todo el estado de hechos, cada uno de los movimientos fácticos que pertenecen a esta circunstancia. Así es como podemos ver que, efectivamente, es apropiado considerar al cuerpo humano en relación con el mundo, si es que queremos obtener claridades con respecto a su manera de ser, pero también estamos un paso más allá de comprender esta relación como una mera interacción entre un sujeto y un objeto. El cuerpo no se reduce sólo a un actuar que se consolida en una situación concreta, donde aún seguiríamos entendiéndolo como una unidad extensa. La aprehensión del campo fenoménico de una ontología del cuerpo, al modo del verbo, nos indica que existe una comunidad aún más radical entre ambos. Podemos ver que en la esfera del trato inmediato pareciera no haber distinción entre cuerpo y mundo, de ahí la importancia de haber realzado su desaparecimiento. Desde esta perspectiva estamos ahora en condiciones de preguntar ¿Cómo es que hay algo como cuerpo en el horizonte de la inmediatez de la vida?

Atendamos nuevamente al beber y veamos qué es aquello que en ese acto gana primacía. No será difícil apreciar que el vaso se me da con diversas texturas y matices luminosos. Podemos destacar, además, que el agua tiene un sabor determinado. En caso que entendiéramos que mediante mi cuerpo anatómico percibo esos datos sensibles, habríamos abandonado nuevamente el nivel de inmediatez que queremos investigar. La sensibilidad aparece fuera de él sólo como una mera función de un agente físico. Sin embargo, en dicha inmediatez vivo, más bien, con las texturas; con la luminosidad, con los sabores, en el sentido de realizarme en las texturas, en la luminosidad o en los sabores. En otras palabras, la sensibilidad desplegada al modo del ver, oír, degustar y tocar, es

\footnotetext{
5 "Das sind einmal die bisher explizierten Weisen des Seins: die Zuhandenheit, die Vorhandenheit, die innerweltlich Seiendes von nicht daseinsmäßigem Charakter bestimmen” (2001:183).
} 


\section{Felipe Johnson}

exactamente aquel modo cómo se despliega un acceso a los entes, y dicho acceso al ente es, al mismo tiempo, la configuración más propia del ente dado.

Afirmamos, entonces: lo que el vaso de agua es, en este nivel inmediato, no es más que lo que yo vivo en mi relación con texturas, luminosidades, sonidos, etc. Ver, escuchar; oír y tocar no nos aparecen ahora como funciones neutras ejecutadas por una cosa extensa que soy yo, sino como el modo de donación más propio del mundo concreto. La sensibilidad, podemos decirlo ahora con Heidegger, es la manera específica cómo yo tengo al mundo, "Weise des Sie- [die Welt] Dahabens" (2002:52), lo que — como vemos - se despliega de diversas maneras, a saber, como "lo visto", "lo oído", "lo tocado", etc. La sensibilidad es, en consecuencia, aquel modo de ser de la vida en donde cuerpo y mundo se nos muestran como un fenómeno único. Ella nos indica cómo el cuerpo se despliega sin mostrársenos como una estructura física. En la sensibilidad hallamos la vitalidad más auténtica de nuestro fenómeno, porque ella es mi manera originaria de relación con un mundo concreto.

En este contexto podemos ver cómo es que una ontología de la corporalidad pareciera ganar un campo fenoménico que se resiste a ser aprehendido mediante las categorías de lo físico. Pareciera ser, de hecho, que una consideración que tenga por objeto el cuerpo humano ha debido cuidarse constantemente de no comenzar desde un suelo asumido sino, más bien, procurar a cada momento que dicho suelo sea expuesto de manera originaria desde su inmediatez. Con esto obtenemos que para la fundación de una ontología de la corporalidad, es no sólo relevante el realce de los caracteres formales de su objeto de estudio, sino, antes que todo, la garantización de aquel tipo de ente que brindará el inicio de la explicitación filosófica.

\section{LÍNEAS DIRECTRICES PARA UNA ONTOLOGÍA DE LA CORPORALIDAD}

Dijimos que en la inmediatez, el puesto más propio para observar el cuerpo humano es la sensibilidad. Será preciso, ahora, profundizar en la relación que existe entre cuerpo y sensibilidad. Para estos fines deberemos entender qué implica que el mundo se nos done al modo de lo visto, lo oído, la textura o el sabor. Cuando me relaciono con un ente, y este se me manifiesta al modo de texturas o luminosidades, no podríamos decir otra cosa sino que estos datos son los límites del ente dado. La sensibilidad es, en cuanto modo de donación, de-limitación y, al mismo tiempo, límites de la constitución del ente en su concretud. Es lo que ahora podríamos llamar - siguiendo las consideraciones de Heidegger sobre Nietzsche (1989:164-171) esquematización (Schematisierung), de manera que cada modo de la sensibilidad (oír, tocar, etc.) se nos muestra, en esencia, como modos específicos de esta esquematización, mientras que lo visto, lo oído, lo tocado, en tanto correlatos de dicha presentación del ente, son lo que llamaremos esquemas. Así vemos que cuerpo y sensibilidad no se equiparan completamente. Deberemos decir que en los distintos modos de la presentación del ente concreto hay un movimiento común. Este 
movimiento, que es la esquematización, es aquello que identificaremos con el fenómeno cuerpo humano, mientras que el despliegue del mundo concreto en diferentes contenidos (sabor, textura, etc.) es aquello que denominaremos sensibilidad. En definitiva, al ser de la sensibilidad le pertenece una tendencia de delimitación que es condición de posibilidad de sus diversos modos de presentación. Esta tendencia, su más propia direccionalidad, es, pues, lo que ahora entenderemos por "cuerpear", término que proponemos como traducción del verbo Leiben, utilizado por Heidegger al referirse al fenómeno del cuerpo humano (1994b:113). ${ }^{6}$

Sin duda alguna parecerá algo violento ocupar el término cuerpo en sentido verbal. Sin embargo, podemos entender - según lo expuesto - que la necesidad de su uso radica en mostrar nuestro fenómeno principalmente como un movimiento. No se trata, no obstante, de que un cuerpo animal realice acciones en su medio, donde cuerpear sería más bien sinónimo de ejecutar. Por cuerpear entenderemos estrictamente esa dirección en la tendencia de esquematizar que es condición de posibilidad formal de la obtención de entes delimitados al modo de los datos sensibles. Dicha direccionalidad caracterizaría la esencia del cuerpo humano. Desde Heidegger podríamos decir, entonces, que el cuerpo sería aquella posibilidad de la vida de asegurarse un suelo donde vivir (2002:199). Sería la posibilidad de ganar para sí aquella capa de-limitada de la experiencia que proporciona el material con el cual la vida humana debe tratar para continuar viviendo. El cuerpo humano sería, en su esencia, la posibilidad vital del despliegue de un mundo, cuya propia concreción son los diferentes modos de lo sensible. Ahora bien, cabe preguntar ¿Cuál es la característica fundamental de estos límites? ¿De qué manera está el mundo delimitado sensiblemente para la vida?

Hemos dicho que cuerpear puede ser entendido como la condición de posibilidad de donación de aquella capa material con la cual la vida cotidiana se relaciona. (Heidegger (1999:210). Diremos que esta relación se da al modo de lo que apremia. ${ }^{7}$ La vida, para vivir concretamente, se confronta con un mundo apremiante, con un mundo que "la arrastra para sí". Un mundo que constantemente le incumbe, siempre en el sentido de ser afectada por las cosas. El mundo de la vida, que es donado mediante la esquematización del cuerpear, viene delimitado en la forma de lo que seduce y cautiva para sí, de lo que impone un mandato de quedarse con él. Por esta razón, ella se pierde en ese mundo sensible, pues vive en sentido propio sólo cuando está sumergida en el apremio. Un

\footnotetext{
${ }^{6}$ No sería inadecuado, según el sentido de las próximas consideraciones, traducir el vocablo Leiben como "tomar cuerpo", puesto que en su relación con un mundo concreto la vida se concretiza, "gana cuerpo" en su movimiento de esquematización. Optamos, sin embargo, por la traducción cuerpear, pues nos interesa realzar el carácter específico de movimiento que posee el fenómeno del cuerpo humano.

${ }^{7}$ Proponemos la palabra "apremio" para lo que Heidegger denomina Bedrängen, pues alude al hecho de que la vida es "apresada" por su mundo. En el trato con éste acaecería un "dejarse arrastrar" por un dónde, en el cual la vida se despliega. A nuestro entender, es lo que Heidegger señala con el término Sich-ziehen-lassen aus einem Wobei. Cfr. (1994a:410).
} 


\section{Felipe Johnson}

carácter esencial del cuerpear se nos hace presente con estas observaciones: en cuanto esquematización, implica ser la delimitación de entes con un carácter de absolutez. Dicho de otra manera: aquel mundo concreto, que al modo del apremio emerge de la esquematización, se presenta como lo primero y lo último para la vida. De aquí podemos entender por qué es que en este nivel desaparece el cuerpo anatómico, que ciertamente es un fenómeno ya desvivificado. No hay ningún tipo de relación de la vida inmediata con él. No es un ente que nace con la inmediatez, sino tardíamente y desde ella, cuando la vida ya ha tomado distancia de su apremio, cuando ella palidece todo lo que estaba viviendo en una circunstancia determinada. Mientras tanto, el mundo concreto de la vida es propiamente concreto en cuanto cautiva apremiando, y en este contexto, según los distintos modos de sensibilidad, mostrándose como lo único. ${ }^{8}$

Lo anteriormente expuesto nos muestra que el cuerpo se caracteriza por ser primariamente un movimiento, en tanto es una direccionalidad de concretización que, por su parte, se despliega al modo de la esquematización. Cuerpear señala un ordenamiento del mundo de la vida concreta en una manera determinada: en una perspectiva. No obstante, no podremos entender aquella perspectiva del mundo en el sentido de una cierta orientación que adquiriría lo físico, cuando un observador se instala en un punto determinado del espacio para observarlo. La perspectiva aquí mentada se relaciona con el modo absoluto de donación del mundo, se refiere a una organización total que adquiere su dirección en la direccionalidad específica del cuerpear que se nos muestra acá como un ordenamiento fundamental: ${ }^{9}$ al ser del cuerpo, en cuanto ordenación, le pertenece, entonces, un estar orientado hacia.

Dicho carácter es el que nos permitirá aclarar ahora la coherencia entre las diversas modalidades de la sensibilidad mencionadas anteriormente. No podemos negar que el ver, el oír, el saborear y el tocar son nombres para distintas esferas de donación. En rigor, sus respectivas presentaciones materiales no pueden ser integradas a otras esferas. El sabor, por ejemplo, no puede ser percibido por la vista, ni por la audición. Lo importante es entender, sin embargo, que tanto el ver, oír, tocar y saborear $-\mathrm{y}$ esto, a pesar de sus diferencias - presentan el mismo mundo. Todos ellos son el modo material cómo el cuerpear, entendido ahora como dirección hacia, despliega de manera concreta, un mundo. ${ }^{10}$ Así, podemos apreciar que cuerpear es, antes que todo,

\footnotetext{
${ }^{8}$ Como podremos ver, el lugar apropiado para interrogar el fenómeno del cuerpo humano, por cierto, al interior de la filosofía de Heidegger, se enmarca en un carácter de la vida fáctica que él denominó "caída" (Verfallen).

${ }^{9}$ Esta caracterización de cuerpo como ordenamiento fundamental es lo que, a nuestro juicio, pareciera estar en juego cuando Nietzsche le denomina "una gran razón" (eine grosse Vernunft) (1999:39).

${ }^{10}$ Así es como Schapp afirma: "Pues esto es a modo provisorio lo maravilloso, a saber, que tonos y colores, así como sensaciones táctiles y de presión, aunque predominan y sean lo más determinado en las áreas perceptivas por ellos asumidas, más aún, aunque sean principalmente diferentes los unos de
} 
una direccionalidad única que, a la vez, se concreta a modo de los esquemas, según los diferentes modos de lo sensible.

La utilización del término cuerpear muestra su precisión en relación con la aprehensión del fenómeno en cuestión. En tanto verbo, no indica primariamente una cosa, sino más bien una dirección. El horizonte de problemáticas que emergen con la utilización del término cuerpear nos impide insistir en la pregunta por el cuerpo, entendido como una cosa presente en un espacio geométrico. Podemos ver, entonces, que una ontología de la corporalidad, desde esta perspectiva, deberá centrarse principalmente en los momentos que le pertenecen al arriba mencionado "estar orientado hacia", que destacábamos como carácter esencial del cuerpo humano. Una ontología de la corporalidad vendría a constituirse ahora, según lo expuesto, en la pregunta por la constitución de aquella dirección de despliegue del mundo concreto.

Volvamos, por última vez, al ejemplo del "beber agua" con el que comenzamos, y retomemos el problema principal que arriba nos salía al paso ¿De qué manera deberemos entender los límites de mi yo en esa mano que quiere alcanzar un vaso de agua? Es importante destacar que este problema se nos presenta ahora de manera distinta. Los límites del yo han dejado de tener relación con un continente físico, como lo exponíamos entonces. Ahora se trataría, más bien, de investigar en qué relación se encuentran el yo y el cuerpear, entendido éste como direccionalidad del mundo concreto o, en otras palabras, cómo es que ese yo caracteriza aquella concreción direccionada del mundo.

Podemos decir que, arrojado en el beber, todo aquello con lo cual me relaciono acusa un único sentido: satisfacer la sed. La cercanía o lejanía del vaso, el vaso como el adecuado o no adecuado, la cantidad de agua como suficiente o insuficiente, todo lo que se abre concretamente en el beber, se concreta al modo de dejar de lado mi sed. Diremos, así, que ese beber es mi beber, la circunstancia en su totalidad es el espacio concreto que, por cierto, se concreta de acuerdo a la realización del yo como posibilidad de volverse algo: en nuestro caso "apartar" la sed. En el beber, mi cuerpear no se mueve al interior de una circunstancia, no hay un traslado de un cuerpo anatómico al interior de un contexto. Más bien, es así como "la circunstancia misma" y la manera cómo ella se concreta sensiblemente vendría a ser la manera cómo el cuerpear se despliega. Es aquí donde veremos que el cuerpo humano se muestra en su manera de ser más propia y que, con Heidegger, podríamos denominar Dasein.

En Sein und Zeit es posible apreciar cómo es que este modo de ser Dasein se caracteriza por ser futuro (325). En vistas a una posibilidad, entendida como un tener que ser que la vida humana ha asumido, ella adquiere los límites de su propio despliegue, puesto que en vistas a ese fin que ha pre-asumido se abre el mundo fáctico al modo de un ahi concreto. Este dejarse acaecer de la vida (Sich

los otros y no haya ningún traspaso desde un área a la otra, sin embargo, presentan lo mismo —el mundo allá afuera — a su propio modo" (1925:35) (Trad., mía). 


\section{Felipe Johnson}

auf sich Zukommen-lassen) es aquel carácter que nos interesa de la manera cómo Heidegger caracteriza a la vida humana, y que dice relación con la realización predeterminada por aquella posibilidad o fin en sí mismo que ha sido asumido. Dasein es aquel modo de ser que guarda una relación necesaria con el futuro (Zukunft), porque ser futuro implica el movimiento de dejarse acaecer para realizar lo que aún no se es, pero que se tiene que ser, y esto siempre en la forma de un ahí concreto. Es así como Heidegger en Grundbegriffe der aristotelischen Philosophie, considera que el sentido adecuado del término griego télos (fin), debería expresarse como un "Ser de tal manera hacia un fin, que este fin constituya el auténtico ahí, determinar a un ente auténticamente en su estado de ser actual" (2002:89) (Trad., mía). ${ }^{11}$ El sentido último del cuerpear, en el caso del beber, nos muestra que su estar orientado hacia, atendería fundamentalmente al fin pre-asumido por la vida, que, por cierto, en cuanto fin, es límite de su propio despliegue.

El "estar orientado" que destacábamos como carácter esencial del cuerpear adquiere, en definitiva, su hacia "siempre en vistas a mi propia posibilidad". Así es como la presentación del mundo concreto, mediante cada donación en el modo de lo sensible (lo visto, oído, tocado etc.), se concretiza como "lo más propio". La direccionalidad del cuerpear soy yo y, esto es, la aceptación de mi entendido como un tener que ser $(\mathrm{Zu}$-Sein), que tiende fundamentalmente a realizarse. El cuerpo es en este sentido afirmación de mi posibilidad al modo de la concreción. La concreción de mi poder ser es el modo cómo cuerpeando dejo acaecer mi más propia posibilidad en la forma de un mundo concreto. Cuerpear nos indica, en definitiva, el hecho de existir al modo de circunstancias concretas, pues de ese modo es como la vida, mi vida, "toma cuerpo". Por esta razón, cada circunstancia que realizo cuerpeando tiene su último horizonte en aquello a lo cual la vida como posibilidad debe tender.

Sin embargo, si quisiéramos ahora profundizar en esta posibilidad última que caracteriza cada concreción, según la cual todo cuerpear se despliega, y que en este sentido se muestra como un fin en sí misma, como un por mor de sí (Worumwillen), nos alejaríamos del fenómeno que investigamos. El hecho de que la corporalidad indique ser la "fijación" de una circunstancia, no significa que dicha circunstancia concreta sea el fin en sí para la vida. Las distintas circunstancias se caracterizan, más bien, por poseer otro tipo de fin: ellas deben ser constantemente superadas. Ese es el modo como es posible la apropiación de un fin último. De esta manera obtenemos otro carácter esencial de la corporalidad: su sentido negativo. Cuerpear es el despliegue de toda circunstancia fáctica, para que ésta no esté más ahí. La esquematización posee, en sí, un movimiento de negatividad, en el sentido de autosuperación. Se despliega como circunstancia, para superarse y así poder

\footnotetext{
${ }^{11}$ En el original encontramos: "Télos besagt also ursprünglich: zu Ende sein so, daß dieses Ende das eigentliche Da ausmacht, ein Seiendes in seiner Gegenwärtigkeit eigentlich bestimmen".
} 
concretarse como una distinta. Cuerpear es una constante superación del ahora en vistas a lo que tiene que ser. Por esta razón, este cuerpear no puede ser ilimitado: los esquemas se subsumen siempre al horizonte del acaecer — podríamos decir con Heidegger-; ; ${ }^{12}$ es decir, la concreción de la circunstancia nace y se desarrolla al interior del poder ser, que es el horizonte del desarrollo de $m i$ vida. El fin de estas circunstancias particulares, lo que ellas exhiben como sus límites jamás será entonces un "por mor de sí", sino más bien un "por mor de otro". ${ }^{13}$ Este es el modo esencial de la direccionalidad del cuerpear: él es el despliegue de diversas circunstancias particulares, realizadas para superarse en el horizonte general de un poder ser por mor de sí mismo. Entendido así, el cuerpo muestra su más radical pertenencia conmigo. El cuerpo no es una cosa que no soy yo, sino que me pertenece de alguna manera. Él es más bien mi propio movimiento de "estar en trabajo dejándome acaecer", la más propia realización de mí en cuanto posibilidad. En definitiva, el cuerpo pertenece a un yo, en la medida en que ese yo implica ser una posibilidad que ha de ser cuerpeando.

En síntesis, con estas consideraciones observamos que la corporalidad, como aseguramiento de un suelo para la vida, se funda en otro rasgo esencial de la misma: ella es garantía de la vida entendida como posibilidad. Este último carácter es la manera cómo la vida se gana su propio suelo: ella implica un dejarse constantemente acaecer, y así realizarse constantemente en su concretud. En consecuencia, el movimiento que pertenece al fenómeno cuerpo humano más propiamente no es el denominado traslado (phorá), sino más bien el acaecer o realizarse (génesis). El cuerpo es esencialmente movimiento, en su sentido primario de ser permanente realización de un fin al modo de lo concreto. Estas consideraciones nos llevan, finalmente, a comprender de qué manera el cuerpo se deja entender como materia, ahora, sin embargo, desde el modo de ser del Hombre, que nosotros con Heidegger llamábamos Dasein. Por tal, no entenderemos una dimensión física (extensa). El cuerpo, en tanto materia, no es aquella dimensión sólida de una "cosa extensa y viva" que llamaremos ser humano. El fenómeno cuerpear nos muestra que el cuerpo ciertamente es concreción, es algo delimitado (Heidegger, 2002:227), pero lo delimitado originariamente es la vida, en virtud de la cual dicha concretud acaece al modo del ordenamiento de circunstancias que mediante la esquematización se consolidan con carácter del apremio. El concepto cuerpo, entonces, se refiere a la consolidación de la vida misma y, por lo tanto, indica más bien, que ésta se da en determinados límites de carácter apremiante. De esta manera, deberemos realzar una diferencia muy sutil que existe entre los

\footnotetext{
${ }^{12}$ En esta dirección es que Heidegger afirma: "Die Schemata übernehmen die Ausbildung des Horizontes" (1989:164).

${ }^{13}$ Dicha distinción la destacamos de las consideraciones de Heidegger sobre Aristóteles, donde se destacan dos tipos de fines: téleion y télos. El primero caracterizado como un "por mor de sí mismo", mientras que el segundo se refiere a un fin que debe ser superado para que sea posible una apropiación de otro (por mor de otro). (Cfr. Heidegger, 2002:91-97).
} 
conceptos cuerpear y cuerpo. El primero indica el movimiento fundamental mediante el cual la vida adquiere su más propia consolidación, mientras que el segundo, cuerpo, indica más bien el estado de la vida de existir, mediante el cuerpear, delimitada en forma concreta según un modo de ser.

Así es como, finalmente, podemos decir que a una ontología de la corporalidad le es posible ganar una perspectiva en la consideración del cuerpo humano, que le permita aprehender su propio objeto de estudio en su auténtica vitalidad, dejando de lado consideraciones que intenten exponerlo mediante las categorías que determinan un objeto presente en un espacio homogéneo. Más que una mera cosa, que es la manera acostumbrada de entenderla, la corporalidad se nos ha mostrado en las discusiones anteriores como una posibilidad de la vida misma, que da cuenta de su concreción primaria. Este punto de partida es, en nuestra opinión, aquel que una ontología de la corporalidad debiera seguir afianzando, si es que el fenómeno del cuerpo humano pretende ser explicitado en su modo más auténtico de despliegue.

Universidad Andrés Bello* Licenciatura en Filosofía Fernández Concha 700, Casona, $2^{\circ}$ piso, Santiago (Chile) ejohnson@unab.cl

BIBLIOGRAFÍA

Aristóteles. Metaphysica. London: Oxford University Press, 1957.

------ Physica. London: Oxford University Press, 1956.

Heidegger, Martin. Grundbegriffe der aristotelischen Philosophie. GA 18. Frankfurt a. M: Vittorio Klostermann, 2002.

------- Sein und Zeit. Tübingen: Max Niemeyer Verlag, 2001.

------ Zur Bestimmung der Philosophie. GA 56/57. Frankfurt a. M: Vittorio Klostermann, 1999.

------ Prolegomena zur Geschichte des Zeitbegriffs. GA 20. Frankfurt a. M: Vittorio Klostermann, 1994a.

------ Zollikoner Seminare. Frankfurt a. M.: Vittorio Klostermann, $1994 \mathrm{~b}$.

------ Grundprobleme der Phänomenologie (1919/20). GA 58. Frankfurt a. M: Vittorio Klostermann, 1992.

----- Nietzsches Lehre vom Willen zur Macht als Erkenntnis. GA 47. Frankfurt a. M: Vittorio Klostermann, 1989.

Merleau-Ponty, Maurice. Phénoménologie de la perception. Paris: Librairie Gallimard, 1945.

Nietzsche, Friedrich. "Also sprach Zarathustra", en Kritische Studienausgabe. Vol. 4. Hrsg. von G. Colli und M. Montinari. München: De Gruyter, 1999.

Schapp, Wilhelm. Beiträge zur Phänomenologie der Wahrnehmung. Erlangen: Verlag der philosophischen Akademie, 1925.

Waldenfels, Bernhard. Das leibliche Selbst. Vorlesungen zur Phänomenologie des Leibes. Frankfurt a. M: Suhrkamp, 2000. 